\title{
ZOOLÓGICOS E AQUÁRIOS: SUA IMPORTÂNCIA CONTEMPORÂNEA
}

\author{
Fernanda Gonçalves Duque ${ }^{1}$ \\ Carolina Santos Ferreira ${ }^{2}$ \\ Vinícius José Laste ${ }^{3}$ \\ Beatriz Laura da Silva ${ }^{4}$ \\ Mariana Serafim Campacci ${ }^{5}$ \\ Beatriz Félix Pacheco ${ }^{6}$
}

Resumo: Os aquários e zoológicos se tornaram de interesse público há centenas de anos. Este trabalho teve como objetivo fazer um levantamento sobre a percepção da população acerca da importância dos zoológicos e aquários. Foram aplicados 935 questionários por meio virtual para indivíduos aleatórios. Quanto aos resultados obtidos $67,4 \%$ dos respondentes consideram importante a existência de zoológicos e aquários e $81,6 \%$ acreditam que estes proporcionam conscientização sobre a importância da conservação das espécies. Além disso, a grande maioria dos respondentes afirma que a extinção de uma espécie afeta negativamente a sociedade $(98,4 \%)$ e aponta a destruição do habitat como maior causa da extinção $(65,2 \%)$.

Palavras-chave: Percepção Ambiental; Zoológicos; Aquários; Educação Ambiental.

Abstract: Aquariums and zoos have become of public interest for hundreds of years. This study has been created to survey the population perception about zoo's and aquarium's importance. A total of 935 questionnaires were applied by virtual platform to random people. Regarding the results obtained $67.4 \%$ of the interviewees consider the existence of zoos and aquariums important; $81.6 \%$ believe that they provide awareness of the importance of species conservation. The great majority has set that extinction of a specie negatively affects society (98.4\%) and point to habitat destruction as the main cause of extinction (65.2\%).

Keywords: Environmental Perspective; Zoos; Aquariums; Environmental Education.

\footnotetext{
${ }^{1}$ Universidade Anhembi Morumbi. E-mail: duque.fernanda.g@gmail.com. Link para o Lattes: http://lattes.cnpq.br/9557162383788961

2 Universidade Anhembi Morumbi. E-mail: carolinasf@live.com. Link para o Lattes: http://lattes.cnpq.br/7893840185223907

3 Universidade Anhembi Morumbi. E-mail: vinicius.jl@hotmail.com. Link para o Lattes: http://lattes.cnpq.br/9457427204935865

4 Universidade Anhembi Morumbi. E-mail: blauradasilva@gmail.com. Link para o Lattes: http://lattes.cnpq.br/2931022111495129

${ }^{5}$ Universidade Anhembi Morumbi. E-mail: mariana.campacci@outlook.com. Link para o Lattes: http://lattes.cnpq.br/1732311991373226

6 Universidade Anhembi Morumbi. E-mail: beatrizffpacheco@gmail.com. Link para o Lattes: http://lattes.cnpq.br/5962137715581640
} 


\title{
Introdução
}

Segundo Jamieson (1985, apud SILVA, 2019, p.8) os primeiros relatos de humanos utilizando animais silvestres vêm dos egípcios, seguidos por relatos na Europa durante a antiguidade pelos séculos V e VIII. Os imperadores usavam destes animais como forma de entretenimento e demonstração de poder. Tais animais eram sacrificados após cada espetáculo. Já os zoológicos de acordo com Fischer et al. (2017, apud SILVA, 2019, p.8):

Já os primeiros zoológicos modernos surgiram no século XVIII em Viena, Madri e Paris, e em Londres e Berlim no século XIX. Enquanto o primeiro zoológico público de Paris, intitulado como "Jardin des Plants" tinha como objetivo capturar animais oriundos de apreensões em circos e eventos. O Zoológico da Sociedade de Londres já buscava a função didática e científica.

Sobre os aquários, os primeiros relatos, vêm dos romanos, que mantinham peixes vivos em tanques de mármore em suas casas, que era um símbolo de status social. Com o tempo, alguns destes tanques passaram a ter suas laterais de vidro, facilitando a visualização dos animais. Já os chineses foram os primeiros a conseguir reproduzir em cativeiro e até criar espécies novas. A descoberta dos ciclos ecológicos permitiu a compreensão da relação entre plantas e peixes, permitindo a criação de técnicas para manutenção destes animais em cativeiro. Segundo Salgado e Marandino (2014, p.7):

\begin{abstract}
Apesar de os antigos tanques de água doce ou salgada terem encontrado espaço entre colecionadores e aristocratas, o aquário surge, especialmente, como uma ferramenta científica. Como as soluções para aeração, manutenção da qualidade da água e viabilização do aquário haviam sido publicadas, inicialmente, em jornais das restritas sociedades científicas da época, apenas os naturalistas conseguiam montar e manter aquários entre 1840 e 1850. Eles serviam, de fato, para a observação de animais vivos e durante intervalos de tempo até então impossíveis.
\end{abstract}

Atualmente, zoológicos e aquários têm como objetivos a conservação, a educação, a pesquisa e o lazer. Estas instituições têm um grande impacto na população, o que, por cascata, impacta em políticas públicas conservacionistas (MARINO, 2008, apud ARAGÃO; KAZAMA, 2013, p.21). As visitações são a chave para conscientização da população, pois geram interesse, conhecimento e cuidado sobre a fauna (local e mundial), transformando estes lugares em centros de Educação Ambiental. Além disso, a visão da sociedade acerca dos 
animais sofreu profundas adaptações com o tempo, como: "o reconhecimento da cognição dos animais retira-os da condição de objetos de um meio, para sujeitos do mesmo, onde diversos aspectos complexos da interação animalhomem-meio passam a ser rediscutidas e reelaboradas" (TANNENBAUM, 1991, apud ARAGÃO; KAZAMA, 2013, p.21).

Cabe a estas instituições reproduzirem animais ameaçados, contribuindo para a pesquisa, a conservação e manutenção de espécies, permitindo que algumas possam ser reintroduzidas na natureza. Neste aspecto, entretanto, encontra-se literatura sugerindo que estes não estão aptos para serem reintroduzidos em seu habitat natural por estarem acostumados com a realidade do cativeiro (SNYDER et al., 1996, apud ARAGÃO; KAZAMA, 2013, p.21). Outra crítica muito relatada é que as espécies que fazem parte de um programa de melhoramento genético internacional são muitas vezes de baixa prioridade de conservação (CONWAY, 2011, apud ARAGÃO; KAZAMA, 2013, p.21).

Existem diferentes conceitos de bem-estar animal, um deles está ligado aos estados subjetivos de sofrimento tais como, tédio, dor, fome, sede e frustração, sendo desencadeados quando os animais são impedidos de realizar algo em que estão altamente motivados (DAWKINS, 1990, apud ARAGÃO; KAZAMA, 2013, p.21). Neste contexto, estas instituições buscaram alternativas para reduzir estresse, depressão e comportamentos anormais das espécies e encontraram resposta no enriquecimento ambiental. Segundo Boere (2001, apud ARAGÃO; KAZAMA, 2013, p.21), enriquecimento ambiental é "uma série de procedimentos que têm como objetivo a modificação do ambiente físico e social, e como resultado, a melhoria da qualidade de vida dos animais que vivem em cativeiro". O enriquecimento ambiental permite que o animal expresse seu comportamento natural, um comportamento que ele possuiria na natureza.

Quanto à exposição de animais, muitas pessoas encontram-se relutantes em manter os animais enjaulados e no tamanho do recinto, mesmo que os ambientes se encontrem mais próximos ao natural (MAUÉS, 2019, p.18). Outras acreditam que estes locais têm como objetivo a exploração dos animais selvagens. Segundo Jamieson (2008, p.52):

Antes de considerarmos as razões pela sobrevivência dos zoológicos, deveríamos ver que há pressuposições morais contra manter animais selvagens em cativeiro. $O$ que isto envolve, afinal, é retirar animais de seu habitat natural, transportá-los por grandes distâncias e mantê-los em ambientes estranhos nos quais sua liberdade é severamente restrita. É verdade que sendo retirados da selva e confinados em zoológicos, os animais são privados de muitos bens. 
instituições, visando o levantamento de dados. Não houve seleção de um grupo específico de pessoas para esta pesquisa, o único requisito era a maioridade legal, logo, os respondentes possuem diferentes crenças, sexos, áreas de atuação, rendas, regiões e formações acadêmicas. Graças a isto, os autores desta pesquisa (profissionais da área) conseguiram entender mais sobre os pensamentos que cercam estas instituições, principalmente com a Câmara Municipal de São Paulo aprovando um projeto de lei (SÃO PAULO. Câmara Municipal de São Paulo. Projeto de Lei PL01-00030/2019) que proíbe a instalação de novos zoológicos e aquários na cidade e estabelece uma série de regras para os já existentes.

Os autores visavam obter respostas dos respondentes para hipóteses como: Os zoológicos e aquários são locais inapropriados? De onde vêm os animais? Quais os objetivos destas instituições? Os animais sofrem maustratos? É certo pagar para entrar nestes locais? Entre outras que serão abordadas ao longo do presente artigo.

\section{Metodologia}

Este trabalho foi realizado em duas fases, sendo feita, no primeiro momento, a pesquisa bibliográfica, onde foram realizadas revisões das literaturas existentes sobre o tema e específicos da área. Pode-se constatar que a maioria das pesquisas abordam as opiniões dos visitantes sobre zoológicos específicos, mas não se verificou estudos voltados para uma visão geral destas. Sobre os aquários percebe-se que a maioria dos estudos são voltadas para a conscientização e Educação Ambiental, já para a pesquisa de opinião sobre esses locais, eles são escassos.

O estudo registrou apenas os fatos observados, sem interferência dos autores, referente ao contexto apresentado ao longo deste trabalho. Foi utilizado o questionário como método de coleta de dados, sendo este um dos principais procedimentos a ser usado em pesquisa descritiva (PRODANOV, 2003, p. 52).

O questionário foi escolhido como forma de obtenção dos dados da pesquisa para entender a opinião das pessoas sobre os zoológicos e aquários existentes em nossa sociedade. Foi enviado de forma eletrônica no período de dez dias (2020) pela plataforma Google Docs devido a sua facilidade de manuseio e tabulação dos dados posteriormente. Não houve um público-alvo específico, sendo a pesquisa enviada a todos aqueles que se interessaram a respondê-la.

Para realizar a análise dos dados dos questionários foi levada em conta, o método quantitativo que busca a análise objetiva e a quantificação dos resultados, estudando exclusivamente uma parcela dela, conforme foi realizado em nosso artigo. A principal razão para escolha desse método de pesquisa foi a avaliação do porcentual de pessoas de uma determinada parcela da população que compartilham ou divergem de uma mesma opinião sobre zoológicos e 
aquários em nossa sociedade (PRODANOV, 2013, p.70; ZANELLA, 2013, p. 95 e 96). questionário:

Abaixo seguem as perguntas e informações que constaram no

A pesquisa abaixo foi desenvolvida pelos alunos do $5^{\circ}$ semestre de Medicina Veterinária da Universidade Anhembi Morumbi com o intuito de identificar qual é a imagem que as pessoas têm sobre os zoológicos e aquários. Trata-se de uma pesquisa de cunho científico, com intuito de publicação via artigo científico em revista específica da área. Por isso, todos os dados fornecidos abaixo serão preservados e não divulgados fora do meio acadêmico.

1) Por favor, informe seu nome completo.

2) Informe sua idade:
a) Até 17 anos
b) De 18 a 25 anos
c) De 26 a 35 anos
d) De 36 a 45 anos
e) De 46 a 55 anos
f) Acima de 55 anos

3) Qual seu gênero?
a) Feminino
b) Masculino
c) Transgênero
d) Não- binário
e) Outro

4) Em qual região você mora?
a) Sudeste
b) Sul
c) Norte
d) Nordeste
e) Centro Oeste

5) Qual seu grau de formação?
a) Ensino fundamental incompleto
b) Ensino fundamental completo
c) Ensino médio completo
d) Ensino superior completo
e) Mestrado/ Doutorado/ Pós- doutorado

6) Qual sua área de atuação?
a) Ciências exatas
b) Ciências humanas
c) Ciências biológicas
d) Outro. Especifique caso tenha marcado a opção outros.

7) Qual a sua faixa salarial?
a) Não tenho renda
b) De até 01 salário mínimo
c) De 01 a 02 salários mínimos
d) De 03 a 04 salários mínimos
e) De 05 a 06 salários mínimos
f) Acima de 06 salários mínimos

8) Qual é o veículo de informação que você mais utiliza na hora de buscar conhecimento? Marque aquela que você mais usa.
a) Internet
b) Televisão
c) Redes sociais
d) Jornais
e) Revistas e artigos científicos

9) Você acredita que os zoológicos e aquários são importantes para a sociedade?
a) $\mathrm{Sim}$
b) Não 
10)Caso tenha marcado a opção Sim da questão anterior: Por quê você acredita que os zoológicos e aquários são importantes para a sociedade? Selecione aquela que julgar a mais verdadeira.
a) Ajuda a população a conhecer as diferentes espécies de animais
b) Ambiente agradável para passeios
c) Uma excelente forma de Educação Ambiental para crianças
d) Estimula o contato com a natureza
e) É um local que proporciona conscientização sobre a importância da conservação de espécies

11)Caso tenha marcado a opção Não da questão anterior: Por quê você acredita que os zoológicos e aquários não sejam importantes para a sociedade? Selecione aquela que julgar a mais verdadeira.
a) Não considera correto manter animais enjaulados
b) Acredita que os zoológicos e aquários passem uma imagem negativa para as crianças
c) Acredita que manter os animais em tais locais seja uma forma de maus-tratos
d) São locais que apenas se beneficiam financeiramente dos animais
e) São locais que retiram os animais da natureza e os expõem para entretenimento das pessoas

12)Qual razão te levaria/levou a visitar um zoológico e um aquário?
a) Diversão
b) Educação
c) Observar os animais
d) Passear com a família ou com os filhos
e) Não gosto de visitar zoológicos e aquários.

13)Ao visitar um zoológico o que aprendeu? Marque aquela que mais se adeque a sua experiência no zoológico e no aquário.
a) Não aprendi nada
b) Que são locais que há conservação e Educação Ambiental
c) Que muitos animais estão em risco de extinção e precisam ser preservados
d) Que os animais estão sendo bem cuidados no zoológico e no aquário
e) Que os animais estão sendo explorados financeiramente pelos zoológicos e aquários

14) Você conhece alguma atividade educativa oferecida pelos zoológicos e aquários dentro ou foras desses locais?
a) Sim, conheço atividades educativas oferecidas dentro dos zoológicos e aquários
b) Sim, conheço atividades educativas oferecidas fora dos zoológicos e aquários
c) Não, desconheço as atividades educativas oferecidas


15) Você conhece as pesquisas científicas que são desenvolvidas ou apoiadas pelos zoológicos e aquários?
a) $\mathrm{Sim}$
b) Não

16) Você acredita que a cobrança de ingressos seja uma prática correta dos zoológicos e aquários?
a) $\mathrm{Sim}$
b) Não

17) Excluindo o fato que o melhor local para os animais selvagens é a natureza, você acredita que os recintos, locais onde ficam os animais para a exposição ao público, são locais adequados para os animais?
a) $\mathrm{Sim}$
b) Não

18)Em quais locais os animais dos zoológicos e aquários são obtidos? Marque mais de uma opção se julgar necessário.
a) Resgate de tráfico/pesca ilegal de animais
b) São retirados da natureza
c) Animais vindos do circo
d) Reprodução de animais do zoológico e aquário
e) Animais de cativeiro

19)Para você a extinção de uma espécie pode afetar negativamente a sociedade?
a) $\mathrm{Sim}$
b) Não

20)Qual é a principal causa na sua opinião que leva a extinção de uma espécie?
a) Caça/pesca
b) Comércio ilegal
c) Destruição de habitat
d) Introdução de espécie invasora

Caso queira receber futuramente 0 resultado dos questionários deixe seu e-mail:

\section{Resultados}

O questionário foi divulgado em meio eletrônico e foi respondido por todos aqueles que se interessaram pela pesquisa. Não houve um número alvo de respostas ou um grupo específico. Recebemos um total de 1.039 respostas durante o período de 10 dias ao qual a pesquisa ficou aberta para receber respostas. Após análise do questionário 935 respostas foram consideradas, pois respostas de pessoas menores de 18 anos, duplicadas, incompletas ou incorretas foram desconsideradas.

Os dados obtidos mostraram que a pesquisa foi realizada predominantemente pela faixa etária de 18 a 25 anos, ou seja, jovens $(67,2 \%)$. Pessoas de 26 a 55 anos representou $28,9 \%$ e acima de 55 anos apenas $4 \%$. No gênero, a maioria era feminino $(79,7 \%)$ e o restante era masculino $(20 \%)$ e $0,3 \%$ se identificaram com outra opção de gênero. A maior parte era da região sudeste com $86,3 \%$ e $13,6 \%$ eram de outra região do país. Já o grau de formação estava dividido entre ensino superior incompleto/cursando (53,5\%) e ensino superior completo $(31,7 \%)$, o que mostra que, em média, $85,2 \%$ dos 
respondentes possuem um grau mais elevado de formação. No ensino médio completo tivemos $9,2 \%$, ensino fundamental $1 \%$ e mestrado ou grau acima com $4,5 \%$.

$\mathrm{Na}$ área de atuação, a maioria com 40,5\% eram da área de ciências humanas, seguido das ciências biológicas (35,9\%) e exatas com (14,5\%). O restante das respostas $(9,1 \%)$ se dividiu em várias áreas de atuação. A faixa salarial que teve mais resposta foi não ter renda $(33,3 \%)$ por conta da maioria ser estudante, seguido por $23,2 \%$ de 01 a 02 salários mínimos, $15,5 \%$ de 03 a 04 salários mínimos, 9,6\% de até 01 salário mínimo, 7,4\% de 05 a 06 salários mínimos. Já aqueles acima de 06 salários mínimos com $11 \%$ das respostas.

A maior parte dos respondentes utiliza como fonte de conhecimento a internet $(78,8 \%)$, ganhando da minoria que utiliza artigos e revistas científicas $(12,5 \%)$. O restante $(8,7 \%)$ utiliza outros meios.

Sobre a questão da importância dos zoológicos e aquários para a sociedade $67,4 \%$ acredita que sim (Gráfico 1) e também foi questionado por qual motivo eles acreditavam em sua importância, então, 81,6\% afirmam ser um local que proporciona conscientização sobre a importância da conservação de espécies; 8,9\% acreditam que é uma excelente forma de Educação Ambiental para crianças e $5,4 \%$ acreditam que ajuda a população a conhecer as diferentes espécies, 3,2\% estimula o contato com a natureza e 1\% é um ambiente agradável para passeios (Gráfico 2).

Você acredita que os zoológicos e aquários são importantes para a sociedade? 935 respostas

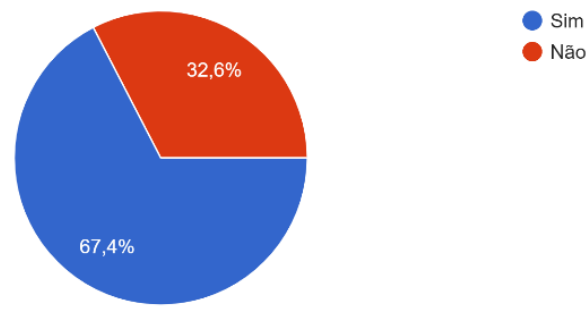

Gráfico 1: opinião do público sobre a importância dos zoológicos e aquários.

Fonte: autoria própria.

Por quê você acredita que os zoológicos e aquários são importante para a sociedade? Selecione aquela que julgar a mais verdadeira. 630 respostas

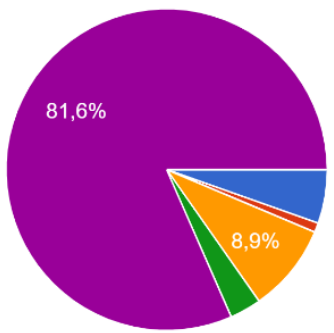

Ajuda a população a conhecer as diferentes espécies de animais

Ambiente agradável para passeios

Uma excelente forma de educação ambiental para crianças

- Estimula o contato com a natureza

- É um local que proporciona conscientização sobre a importância da conservação de espécies

Gráfico 2: opinião do público que respondeu sim no Gráfico 1.

Fonte: autoria própria. 
Tivemos o interesse em saber a opinião das pessoas que colocaram a opção que estas instituições não são importantes (32,6\% no Gráfico 1) e as respostas obtidas ficaram entre $38 \%$ justificando que seria um lugar que retiram os animais do seu habitat natural e os expõem para entretenimento das pessoas, $35,4 \%$ que não consideram correto manter os animais enjaulados. Outros $15,7 \%$ acreditam que manter os animais em tais fundações seja uma forma de maustratos e 10,8\% pensam em zoológicos e aquários como locais que se beneficiam dos animais (Gráfico 3).

Por quê você acredita que os zoológicos e aquários não sejam importante para a sociedade?

Selecione aquela que julgar a mais verdadeira.

305 respostas

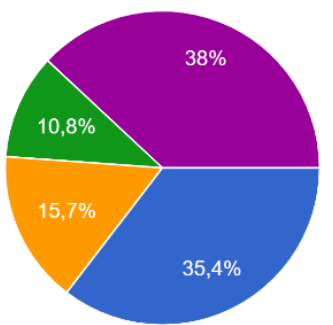

Não considera correto manter animais enjaulados

Acredita que os zoológicos e aquários passem uma imagem negativa para a..

Acredita que manter os animais em tais locais seja uma forma de ma $\lrcorner s-t r a t o s$

- São locais que apenas se beneficiam financeiramente dos animais

São locais que retiram os animais da natureza e os expõem para entreteni..

Gráfico 3: opinião do público que respondeu não no Gráfico 1.

Fonte: autoria própria.

Acerca da razão que levou essas pessoas a visitarem esses locais, com a opção de o respondente selecionar mais de uma resposta, o maior número, com 501 marcações, foi para observar os animais, seguido de educação (450), passear com família ou com os filhos (412), por diversão (249) e por último não gostar de visitar essas instituições com 217 marcações (Gráfico 4).

Qual razão te levaria/levou a visitar um zoológico e um aquário? Marque mais de uma opção se julgar necessário.

935 respostas

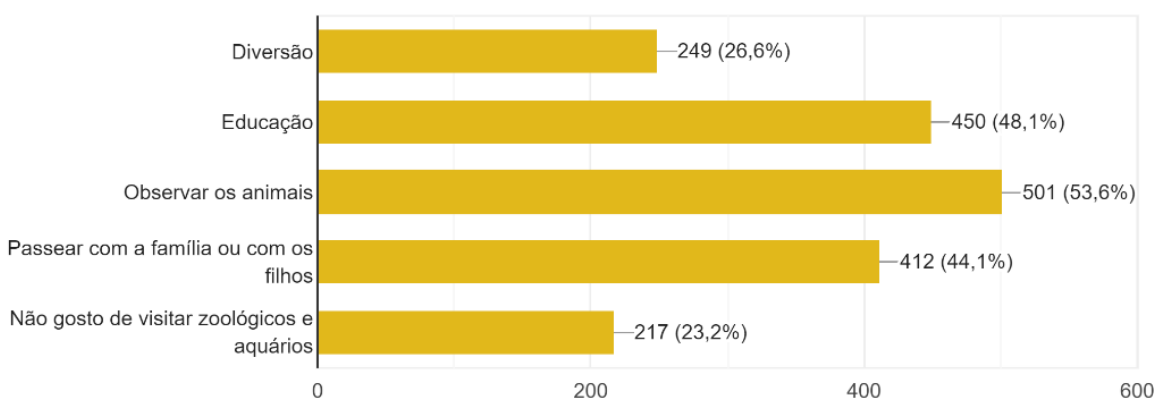

Gráfico 4: razões que levaram os respondentes a visitarem zoológicos e aquários.

Fonte: autoria própria.

Os respondentes informaram que, quando questionados sobre o que aprenderam ao visitarem estas instituições, e com a opção de o respondente selecionar mais de uma resposta, muitos animais estão em riscos de extinção (645 marcações) e que são locais de educação e conservação de espécies com 388. Houve 249 na opção em que os animais estão sendo bem cuidados. Outros 
(259) que acreditam que os animais são explorados nesses locais e 65 marcações informaram que não aprenderam nada durante a visita (Gráfico 5).

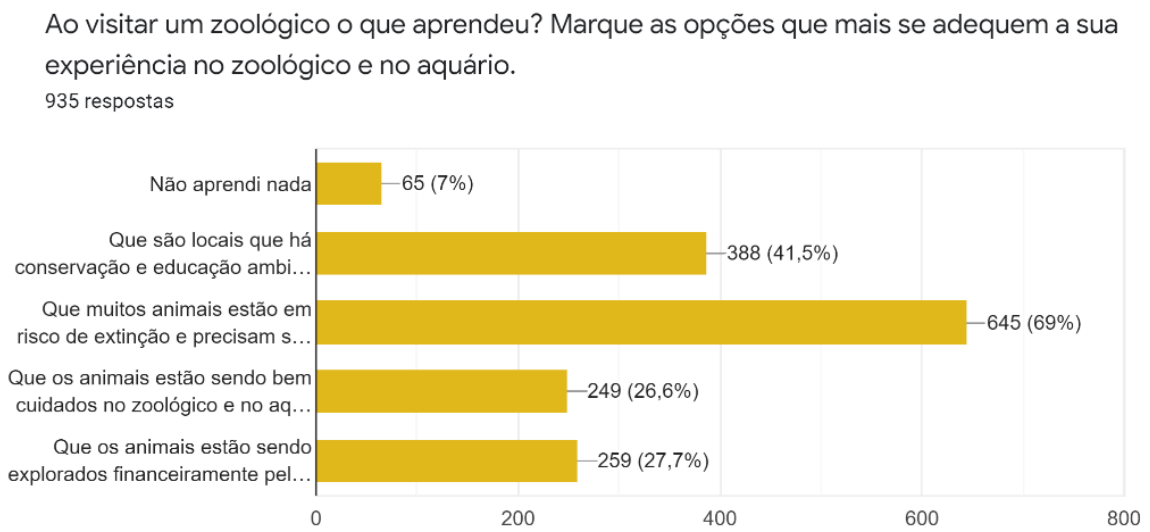

Gráfico 5- aprendizado adquirido ao visitarem aquários e zoológicos.

Fonte: autoria própria.

Nosso questionário obteve que $69,4 \%$ não tinham o conhecimento de pesquisas científicas desenvolvidas por esses locais ou apoiadas por eles, enquanto outros 30,6\% conhecem (Gráfico 6). Levando em conta o conhecimento em relação às atividades educativas oferecidas tanto fora quanto dentro dessas fundações, as respostas foram: $57,1 \%$ não tinham conhecimento, $34,8 \%$ conheciam as de dentro desses locais e $8,1 \%$ tinham conhecimento delas fora dessas instituições (Gráfico 7).

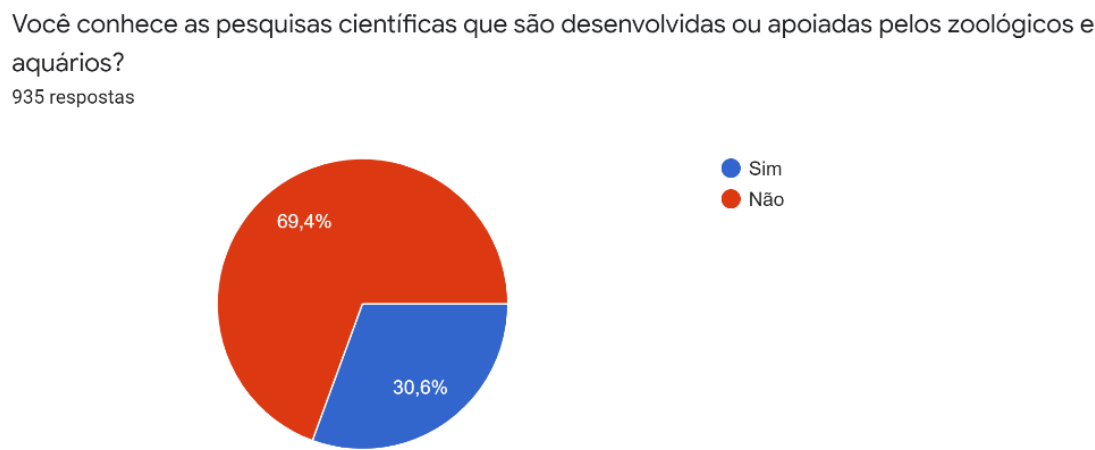

Gráfico 6: conhecimento do público sobre pesquisas científicas em zoológicos e aquários

Fonte: autoria própria.

Você conhece alguma atividade educativa oferecida pelos zoológicos e aquários dentro ou foras desses locais?

935 respostas

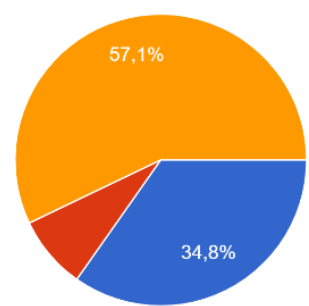

Sim, conheço atividades educativas oferecidas dentro dos zoológicos e aquários

Sim, conheço atividades educativas oferecidas fora dos zoológicos e aquários

Não, desconheço as atividades educativas oferecidas

Gráfico 7: conhecimento do público sobre atividades educativas oferecidas.

Fonte: autoria própria.

Revbea, São Paulo, V.16, № 5: 08-26, 2021. 
Sobre os recintos, $65,7 \%$ acreditam que não atendem às necessidades dos animais e 34,3\% afirmam estar adequados para os animais (Gráfico 8). Em relação à procedência destes, com a opção de selecionar mais de uma alternativa pelo respondente, a maioria (706 marcações) julgou que são animais de resgate de tráfico ou pesca ilegal, 652 acreditam que é pela reprodução destes nos zoológicos e aquários, 605 que são animais de cativeiro, 533 são animais vindos dos circos e, por último, 278 marcações que julgam que são retirados da natureza (Gráfico 9).

Excluindo o fato que o melhor local para os animais selvagens é a natureza, você acredita que os recintos, locais onde ficam os animais para a expo...ao público, são locais adequados para os animais? 935 respostas

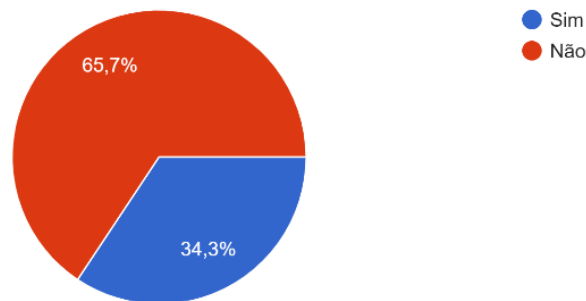

Gráfico 8: opinião do público sobre os recintos

Fonte: autoria própria.

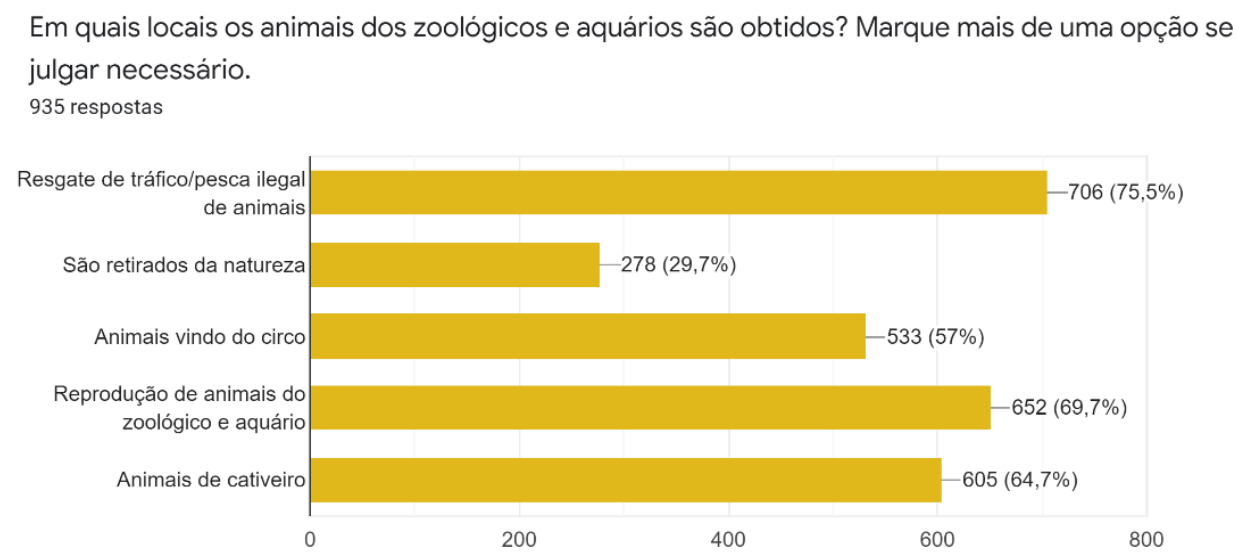

Gráfico 9: resposta dos respondentes sobre os locais que os animais são obtidos.

Fonte: autoria própria.

Em relação à prática da cobrança dos ingressos $77,5 \%$ afirmam ser uma conduta correta e $22,5 \%$ não. Por fim, a grande maioria $(98,4 \%)$ tinha o conhecimento prévio de que a extinção de uma espécie pode afetar negativamente a sociedade, enquanto $1,6 \%$ não tinha. A maior parte dos participantes $(65,2 \%)$ admite que o principal fator que leva à extinção de uma espécie é a destruição do habitat, porém, obtivemos caça/pesca (17,4\%) e comércios ilegais $(15,8 \%)$ como possíveis causas. Apenas $1,5 \%$ acreditam que a introdução de uma nova espécie invasora é a principal causa de extinção de uma espécie. 


\section{Discussão}

O artigo mostrou, de forma geral, que as pessoas são a favor da existência dos zoológicos e aquários, e percebem a importância desses lugares no processo de educação, conscientização e preservação ambiental. Notou-se também que a maior parte desconhece as pesquisas e trabalhos científicos realizados por estas instituições.

A maior parte dos participantes são jovens com grau de escolaridade de ensino superior completo ou cursando, ou seja, são indivíduos que se diferenciam em relação ao seu nível de instrução, por isso, espera-se que os respondentes sejam pessoas mais esclarecidas com assuntos polêmicos como o tema desse estudo. A maior parte daqueles que afirmaram considerar tais instituições de grande importância enxergam que são locais que proporcionam conscientização sobre a conservação das espécies, o que se justifica quando analisamos o Gráfico 5 sobre o que elas aprenderam ao visitar o zoológico, pois a maior contagem foi na alternativa que diz que muitos animais estão em risco de extinção, indicando que eles conseguem transmitir aos seus visitantes esta informação.

Já aqueles que são contra a existência destes locais, em sua maior parte, acreditam que os animais residentes de tais, são retirados da natureza, seguido por aquelas que acham errado manter um animal enjaulado. A ideia sobre animais retirados da natureza pode se justificar pelo fato de que, antigamente, a proposta dos zoológicos era apenas de entretenimento sem preocupação com o bem-estar dos animais. Porém hoje, a função desses locais foi totalmente modificada e os animais não são mais retirados da natureza, sendo sua origem de outros locais como resgate de tráfico ilegal de animais, por exemplo. Outro ponto a se destacar foi a contagem considerável de pessoas que acreditam que os animais são oriundos dos Circos e essa visão surge, pois em décadas passadas era comum o uso de animais selvagens em espetáculos, contudo, atualmente, já há Estados que proíbem o uso de animais em circos, além de existir um Projeto de Lei Federal (PL no 6.445, de 2005, Art. 1 e 2) que pretende proibir o uso de animais nestes locais.

Pode-se constatar que a maioria dos respondentes, a favor ou contra à existência de zoológicos e aquários, usam qualquer fonte da internet como forma principal de obter seus conhecimentos, mostrando que esse público apesar de ter um nível maior de educação não busca fontes confiáveis de informação, o que pode justificar o fato deles não possuírem conhecimento sobre as pesquisas científicas, processos educacionais oferecidos pelas instituições e origem dos animais em cativeiro.

Outra questão a ser mencionada são os recintos. A maioria acredita que são inadequados aos animais. Para a elaboração desses locais muitos zoológicos e aquários possuem um departamento específico para desenvolver um melhor ambiente com uso de enriquecimento ambiental para evitar estresse dos animais, porém o fato desta crença ocorrer deve-se a provável falta de informação oferecida ao público ao visitarem essas organizações, sendo este 
um papel destas, além de inteirar seus visitantes sobre todos os procedimentos e estudos feitos para atender o bem-estar dos animais.

Sobre as bibliografias encontradas, notou-se em Zeni e Barbosa (2007) a percepção ambiental entre visitantes e funcionários do Zoológico Pomerode em Santa Catarina. A maioria dos visitantes percebe a importância deles como instituições conservacionistas por abrigarem e reproduzirem espécies ameaçadas de extinção. Apesar deste reconhecimento, as pessoas visitam estes locais como uma forma de lazer em família e com amigos (o que difere do nosso estudo, que aponta observar os animais e educação os principais objetivos dos zoológicos), relatando que tais lugares não expõem de forma clara suas metas educacionais e de pesquisa como podemos perceber neste artigo.

Os visitantes também relataram, segundo Zeni e Barbosa (2007), que os recintos devem parecer o mais natural possível com o habitat dos animais. A pesquisa foi feita em 2007, e isto demonstra como, em 2020, o Brasil ainda está carente da disseminação do conhecimento quando comparamos este estudo com nosso artigo no quesito de a maioria acreditar que são locais inadequados, logo, as demais metas e atividades desenvolvidas não são tão perceptíveis ou refletidas pelos visitantes, confirmando a falta de informações, as quais podem ser transmitidas através de programas educativos ou pelo uso do marketing e propaganda. Já os funcionários apontaram as atitudes inadequadas dos visitantes, afirmando que o zoológico tem um papel de Educação Ambiental muito forte e isso poderia ajudar os visitantes a mudarem seus comportamentos durante sua visitação. Nosso estudo não focou nesse quesito, mas é interessante perceber que isto deve ser algo a ser considerado por tais estabelecimentos, visto que gera um melhor bem-estar aos animais.

Em outro estudo, De Oliveira Costa (2004) discutiu a importância de relatar as experiências dos programas de Educação Ambiental de determinados zoológicos brasileiros. Atualmente, a maior parte dos zoológicos brasileiros realizam programas de Educação Ambiental que, muitas vezes, são responsáveis pelo aumento do número de visitantes, principalmente de escolas. Em sua pesquisa Auricchio (apud DE OLIVEIRA COSTA, 2004, p.4) obteve como resultado que $77 \%$ dos zoológicos apresentavam trabalhos de Educação Ambiental. Atualmente, não se pode manter um zoológico apenas para abrigar animais. Na programação de muitos zoológicos de acordo com Telles (apud DE OLIVEIRA COSTA, 2004, p.4) a Educação Ambiental já está incluída, sendo uma das formas mais competentes para modificar a mentalidade de ver os animais apenas como bonecos enjaulados.

Ainda no estudo De Oliveira Costa (2004), podemos perceber os trabalhos voltados para a Educação Ambiental no Zoológico de Curitiba (que realiza visitas a hospitais e instituições de assistência aos deficientes físicos e mentais), além dos trabalhos feitos no Zoológico de Sorocaba (um dos primeiros zoológicos do Brasil a implantar um programa de Educação Ambiental sendo referência) e no Zoológico de Belo Horizonte (realiza um projeto para informar sobre o enriquecimento ambiental nos recintos). Apesar da quantidade de 
atividades voltadas para a Educação Ambiental, nossa pesquisa aponta que a maioria das pessoas desconhece estes estudos e trabalhos, mesmo com a forte união entre Educação Ambiental e escolas. Podendo explicar as opiniões das pessoas contra os zoológicos e aquários.

Referente ao estudo de Furtado e Branco (2003) teve como objetivo avaliar a percepção ambiental dos visitantes dos Zoológicos Cyro GevaerdSantur, Fundação Hermann Weege, Parque ecológico e Zoobotânico de Brusque e Parque Beto Carrero World, todos localizados no estado de Santa Catarina. Segundo os autores $94 \%$ dos visitantes concordaram que os zoológicos eram um local adequado para o desenvolvimento de programas de Educação Ambiental. Ainda, $85 \%$ dos visitantes responderam que a extinção de uma espécie é capaz de influenciar direta ou indiretamente em suas vidas, e quando indagados sobre a principal causa que levaria uma espécie a ser extinta, $43 \%$ dos visitantes dos quatro zoológicos atribuíram as extinções à destruição do habitat. Em nosso artigo, esse percentual foi ainda mais elevado onde $98,4 \%$ dos respondentes responderam que a extinção de uma espécie afeta negativamente a sociedade, e $65,2 \%$ disseram que a destruição do habitat é a principal causa que levaria a essa extinção. Evidenciando um maior consenso entre a população a respeito desse tema delicado e importante.

Já no estudo de Bosa, Lopes e Silva (2011) o propósito foi analisar a perspectiva ambiental dos visitantes do Zoológico Municipal de Curitiba. Quando os visitantes foram indagados sobre a importância dos zoológicos, 94\% afirmaram que a existência do zoológico é fundamental, pois segundo eles tratase de um ambiente propício para a Educação Ambiental e reprodução de espécies. Em nosso artigo foram obtidos valores abaixo, onde $67,4 \%$ dos respondentes consideravam estas instituições como importantes para a sociedade, esse valor pode ser explicado devido ao fato da pesquisa dos autores ter sido feita somente com visitantes do zoológico, logo eles estariam mais interessados e informados sobre os mesmos, enquanto a nossa pesquisa foi feita com cidadãos aleatórios sendo, teoricamente, mais fidedigna em relação à opinião da população em geral.

Já o público que se diz contra a existência dos aquários e zoológicos podemos utilizar as ideias de Luzardi (2016) que realizou uma monografia sobre a necessidade da extinção dos zoológicos. Em suma, afirma que os zoológicos deveriam ser abolidos por serem inconstitucionais e exercerem uma visão antropocêntrica. Ainda, afirma que um dos motivos para visitação de um zoológico é a educação, mas segundo a autora estamos instruindo as crianças que manter animais enjaulados é permitido, pois ensina que os animais são meros objetos, sendo um ato de deseducação em nossa sociedade e que podemos ensinar nossas crianças de formas diferentes como palestras, filmes, entre outras. Esta ideia contradiz trabalhos existentes que afirmam que tais locais servem, na realidade, como lugares para exercer a Educação Ambiental e aumentar a percepção de adultos e crianças sobre a importância de se preservar o meio ambiente e os animais. $O$ uso de filmes e palestras são bem- 
vindos, mas a vivência no ambiente real exerce muito mais impacto do que um ambiente virtual ou imaginário.

Sobre a questão da pesquisa Luzardi (2016) afirma que não é válido estudar animais em ambientes artificiais, sendo as melhores pesquisas in loco, ou seja, na natureza em seu habitat natural, pois um estudo em local sintético gera uma pesquisa igualmente artificial. Menciona ainda que poucos zoológicos apoiam ou realizam pesquisas científicas. Entretanto, muitos dos animais estudados pelos zoológicos são espécies em extinção, ou seja, são raras de serem encontradas na natureza, sendo assim seu estudo é limitado, e ainda há as espécies já extintas na natureza por diversos fatores, sendo o zoológico o único local capaz de estudar e preservar tais espécies. Logo, a afirmação da autora vai contra nosso estudo e as bibliografias científicas existentes atualmente, que afirmam que grande parte dos zoológicos mantém estudos e trabalhos científicos.

Outro ponto citado seria a preservação de espécies. Segundo Jamieson (apud LUZARDI, 2016, p. 18), continua-se retirando mais animais da vida selvagem do que devolvendo a natureza. Tais animais se reproduzem dentro dos zoológicos, em ambientes artificiais, e uma vez criados assim, não podem sobreviver à natureza e o ciclo se repete. O problema dessa afirmação é a questão ambiental em que vivemos atualmente, seja pelas queimadas, poluição de mares e rios, destruição dos habitats ou tráfico ilegal de animais. Assim, a problemática não se restringe apenas aos zoológicos, mas sim à sociedade como um todo. Talvez o cenário pudesse ser outro se a preservação ambiental fosse prioritária na humanidade.

A respeito dos recintos, Luzardi (2016) diz que o uso de árvores, rochas artificiais e o que for necessário, na tentativa de deixar o cenário o mais real possível, é uma questão hierárquica do homem que pretende atender os visitantes e não os animais. Para ela, estes locais retiram o comportamento natural, gerando apatia e tristeza nos animais. As afirmações da autora vão de encontro às bibliografias existentes devido à preocupação com o bem-estar dos animais, além dos zoológicos buscarem profissionais capacitados para exercer o enriquecimento ambiental deles. Os recintos atualmente são planejados para atender as exigências de cada espécie e não as dos visitantes. Além disso, a ideia de que os animais estão tristes e apáticos segue uma visão antropológica, ou seja, são sentimentos e percepções humanas que não podemos compará-las aos animais que absorvem e compreendem o mundo à sua maneira.

No artigo de Maués e Maline (2019, v5, n15), foi levantada a questão "Os zoológicos deveriam existir?" entre estudantes do curso de pedagogia. Tal estudo apresenta relatos dos alunos, onde alguns eram contra a existência dos zoológicos, outro a favor e um acredita que sua resposta depende do local. Daqueles que se posicionaram contra, foi abordado a ideia de limitar a área de um animal selvagem ao invés de viverem na natureza; que não deveriam existir animais de outros continentes, apenas os brasileiros; que deveria haver controle de visitação para reduzir o estresse e que a localização dos recintos poderia ser 
analisada a fim de não colocar presas e predadores próximos e, por fim, que a reintrodução dos animais na natureza não seja eficiente. Enquanto isso, a estudante que é a favor destes locais aprendeu que os animais eram oriundos do tráfico ilegal e não sobreviveriam na natureza sozinhos, além da existência de estudos sobre a reprodução de animais ameaçados em cativeiro. Já a entrevistada que se mostrou em dúvida, afirma que sua opinião depende do zoológico, pois os categorizados como "bons" se preocupam com o bem-estar animal e englobam a Educação Ambiental e a preservação de espécies, enquanto os "maus" apenas exploram e maltratam os animais.

Por último, podemos mencionar o trabalho de Artigas e Fischer (2019) que analisaram o impacto que os visitantes do Zoológico de Curitiba causaram no bem-estar dos animais, além de obterem suas opiniões sobre o recinto. Constatou-se que os visitantes enxergavam certas limitações no recinto como também sugeriram mudanças para melhorar o nível de bem-estar, porém não relacionaram sua presença como fator de estresse. Em nosso estudo, não houve levantamento bibliográfico a respeito dessa ideia. Contudo, trata-se de uma perspectiva instigante que deveria ser estudada em profundidade pelos zoológicos e aquários em estudos futuros.

De acordo com o trabalho publicado por Leite (2018), compartilhar ideias falsas atrapalha a diferenciação entre mentira e verdade. Seguindo essa lógica, o artigo buscou saber qual era a principal fonte de conhecimento utilizada pelos respondentes e obteve que 737 pessoas (78,8\%) utilizam a internet, $117(12,5 \%)$ usa artigos científicos e 44 (4,7\%) conseguem informações através de redes sociais. Por isso, deve-se ressaltar a dificuldade em partilhar informações corretas sobre os zoológicos e aquários em meios virtuais. Seguindo este raciocínio, existem leis que regem o funcionamento destes locais, logo é errôneo acreditar que os animais possuem recintos inadequados (lei $n^{\circ} 7.173$, de 14 de dezembro de 1983, art. 8 e art. 9) ou afirmar que os animais são sempre retirados da natureza ou são retirados sem nenhum controle de seu habitat natural (lei $\mathrm{n}^{0}$ 7.173, de 14 de dezembro de 1983, art. 11), além de que praticar maus-tratos contra os animais silvestres é configurado crime contra o meio ambiente (lei $n^{\circ}$ 9.605, de 12 de fevereiro de 1998, art. 32).

Entre as vantagens e limitações de nossa pesquisa, podemos apontar a técnica do questionário virtual em gerar um maior alcance geográfico como uma vantagem, assim como a rapidez em obter as respostas, a liberdade do respondente em expor suas crenças e opiniões dentro da sua disponibilidade de tempo e as respostas uniformes. Apesar do esforço em formular questões claras e objetivas, reconhecemos a possibilidade de ocorrer dificuldades na compreensão por parte de alguns participantes, já que não há entrevistador conduzindo o instrumento. Além disso, aqueles que não usam a internet no seu cotidiano ou que não tem familiaridade com a plataforma infelizmente foram excluídos.

Sobre as nossas hipóteses todas foram respondidas conforme as informações apresentadas ao longo do artigo. 


\section{Conclusões}

Pode-se perceber que, comparando nosso estudo com a bibliografia existente, o público em geral enxerga a importância dos zoológicos e aquários, contudo, desconhece os trabalhos científicos e programas educacionais. Logo, estes locais deveriam investir em uma melhor divulgação visando desmistificar informações incorretas. Além disso, os aquários carecem de estudos voltados para a opinião do público, sendo uma proposta de pesquisa futura.

Sobre uso da internet como fonte de informação, percebe-se, com base no que foi apresentado, que seu uso contribui para um conhecimento, muitas vezes, não confiável. Por isso, os zoológicos e aquários podem utilizar-se desse veículo de informação para transmitir seus conhecimentos e minimizar ideias ruins e falsas sobre essas instituições.

Por fim, dentre os objetivos da Educação Ambiental, o despertar de uma consciência ecológica está profundamente relacionado com a função dos zoológicos e aquários na sociedade.

\section{Referência}

ARAGÃO, G. M. O.; KAZAMA, R. A função dos zoológicos nos dias atuais condiz com a percepção dos visitantes. Educação Ambiental em Ação, v. 43, p. 21, 2013.

ARTIGAS, N. A. S.; FISCHER, M. L. Limitações no cativeiro quanto a promoção de bem-estar em primatas na percepção do visitante do Zoológico de Curitiba. Revista Brasileira De Educação Ambiental (RevBEA), v.14, n.1, p.49-68, 2019.

BRASIL. Projeto de Lei Federal no 6.445, de 2005. Proíbe a utilização de animais em espetáculos circenses ou de qualquer natureza, bem como a entrada no Brasil de companhia circense ou similar estrangeira, caso tenha animais incluídos em suas apresentações. Disponível em: $<$ https://www.camara.leg.br/proposicoesWeb/prop mostrarintegra;jsessionid=1 FD479B9E19774E85A53123A4462BF96. node1 ?codteor $=366646 \&$ filename $=\mathrm{Av}$ ulso+-PL+6445/2005>. Acesso em: 17 de jan. 2021.

BRASIL. Lei $\mathbf{n}^{\circ} \mathbf{7 . 1 7 3}$, de 14 de dezembro de 1983. Dispõe sobre o estabelecimento e funcionamento de jardins zoológicos e dá outras providências.

São Paulo. Disponível em: <http://www.planalto.gov.br/ccivil 03/leis/19801988/l7173.htm >. Acesso em: 19 de jun. 2020.

BRASIL. Lei $\mathbf{n}^{\circ} \mathbf{9 . 6 0 5}$, de 12 de fevereiro de 1998. Dispõe sobre as sanções penais e administrativas derivadas de condutas e atividades lesivas ao meio ambiente, e dá outras providências. São Paulo. Disponível em: $<$ http://www.planalto.gov.br/ccivil 03/LEIS/L9605.htm\#: :text=Art.,a\%20um\%20 ano\%2C\%20e\%20multa>. Acesso em: 19 de jun. 2020. 
BRASIL. Projeto de lei 01-00030/2019 do Vereador Reginaldo Tripoli (PV), de 15 de março de 2019. Dispõe sobre normas de funcionamento dos zoológicos e similares situados no âmbito do Município de São Paulo e dá outras providências. Disponível em: <https://www.vereadortripoli.com.br/projeto-delei>. Acesso em: 19 de jun. 2020.

DE OLIVEIRA COSTA, G. Educação Ambiental-Experiências dos Zoológicos Brasileiros. REMEA-Revista Eletrônica do Mestrado em Educação Ambiental, v. 13, 2004.

FURTADO, M. H. B.C; BRANCO, J. O. A percepção dos visitantes dos zoológicos de Santa Catarina sobre a temática ambiental. In: II Simpósio Sul Brasileiro de Educação Ambiental, 7., 2003, Santa Catarina. Anais [...]. I Encontro da Rede Sul Brasileira de Educação Ambiental, I Colóquio de Pesquisadores em Educação Ambiental da Região Sul. Itajaí: Universidade do Vale do Itajaí, 2003. Disponível em: <http://www.avesmarinhas.com.br/10.pdf>. Acesso em: 30 maio.2020.

JAMIESON, D. Contra zoológicos. Revista Brasileira de Direito Animal, v. 3, n. $\quad 4, \quad$ p. 1-12, Dec.2008. Disponível em: $<$ https://periodicos.ufba.br/index.php/RBDA/article/view/10457/7462>. Acesso em: 14 jun.2021.

LEITE, A. F. A. O dano causado em virtude da circulação de notícias falsas. 2018. 43 f. Trabalho de Conclusão de Curso (Graduação em Direito) Faculdade de Direito de Brasília, Universidade de Brasília. Brasília.

LOPES, L.; BOSA, C. R.; SILVA, J. D. Percepção ambiental dos visitantes do Zoológico Municipal de Curitiba-PR. Revista Monografias Ambientais, v. 4, n. 4, p. 866-876, 2011.

LUZARDI, C. Da necessária abolição dos zoológicos: perspectivas desde a Constituição Federal de 1988. Trabalho de Conclusão de Curso (Graduação em Direito) - Faculdade de Direito do Rio Grande, Universidade Federal do Rio Grande. Rio Grande, 2016.

PRODANOV, C. C. Metodologia do trabalho científico [recurso eletrônico]: métodos e técnicas da pesquisa e do trabalho acadêmico. Rio Grande do Sul: Cleber Cristiano Prodanov, Ernani Cesar de Freitas. 2. ed. Novo Hamburgo: Feevale, 2013. $\quad$ E-book. $277 \quad$ p. Disponível em: $<$ https://aedmoodle.ufpa.br/pluginfile.php/291348/mod resource/content/3/2.1E-book-Metodologia-do-Trabalho-Cientifico-2.pdf>. Acesso em: 30 maio.2020.

MAUÉS, E.; MALINE, C. O Zoológico Como Questão Sociocientífica. Revista Brasileira de Educação Básica, v. 4. n.15, p. 1-8, 2019.

SALGADO, M. de M.; MARANDINO, M. O mar no museu: um olhar sobre a educação nos aquários. História, Ciências, Saúde-Manguinhos, Rio de Janeiro, jul. $1998 . \quad$ Disponível em: $<$ https://www.scielo.br/j/hcsm/a/FBLRqcCFqY7ZPJDYzv5GfDK/?lang=pt\&forma $\underline{\mathrm{t}=\mathrm{pdf}}>$. Acesso em: 11 jun.2021.

revista brasileira educação ambiental 
SILVA, A. Importância dos zoológicos visando o bem-estar de animais silvestres e exóticos. 2019. 24f. Trabalho de Conclusão de Curso (Bacharel em Medicina Veterinária) - Faculdade de Medicina Veterinária de Gama, Centro Universitário do Planalto Central Aparecido dos Santos, Distrito Federal.

ZANELLA, L. C. H. Metodologia de pesquisa. 2.ed. Florianópolis: Liane Carly Hermes Zanella, 2013. $134 \mathrm{p}$.

ZENI, A. L. B.; BARBOSA, D. B. P. Percepção Ambiental No Zoológico Pomerode Sob A Óptica De Visitantes E Funcionários. 2007. 85 f. Anais do IV Encontro "Pesquisa Em Educação Ambiental, Universidade Regional de Blumenau, Santa Catarina, 2007. Disponível em: $<$ http://www.epea.tmp.br/epea2007 anais/pdfs/plenary/TR85.pdf $>$. Acesso em: 8 jun. 2020. 